\section{Military Technical College Kobry El-Kobbah, Cairo, Egypt.}

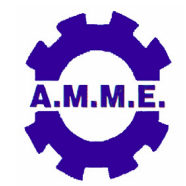

\title{
FLOW BEHAVIOUR AND MICROSTRUCTURAL EVOLUTION OF TITANIUM Ti-10V-2Fe-3AI ALLOY DURING HOT COMPRESSION TEST
}

\author{
H. Al-Salihi ${ }^{(1),(a)}$, C. Bettles ${ }^{(1), \text { (b) }}$ and B. Muddle ${ }^{(1),(c)}$
}

\begin{abstract}
Hot workability characteristics and microstructural evolution of Ti-10V-2Fe-3Al alloy have been investigated extensively by means of hot compression tests over a practical range of temperatures from $760^{\circ} \mathrm{C}$ to $870^{\circ} \mathrm{C}$ with strain rates $(0.01,0.1$, and 1) $s^{-1}$. Activation energy was obtained (using the peak stress values) to determine the material constants and subsequent Zener-Holloman parameter. The dependence of peak stress on the deformation temperature and strain rate obeys a hyperbolic sine equation with the Zener- Holloman parameter. The results show that higher activation energy was observed at a temperature of $800^{\circ} \mathrm{C}$. Microstructural observations of the deformed samples show elongated grains with a recovered structure at lower temperatures. However, recrystallized grains were observed obviously at $810^{\circ} \mathrm{C}, 850^{\circ} \mathrm{C}$ and $870^{\circ} \mathrm{C}$, at a strain rate of $1 \mathrm{~s}^{-1}$. Furthermore, there was a gradual increase in the fraction of recrystallized grains as the deformation temperature increased at higher strain rate. Fracture behaviour during hot compression test was also investigated optically in terms of surface cracks at different deformation conditions. In terms of this damage behaviour, surface cracks were observed at $760^{\circ} \mathrm{C}$ with higher strain rate $1 \mathrm{~s}^{-1}$.
\end{abstract}

\section{KEY WORDS}

Activation Energy, Recrystallization, Damage, Titanium.

(1) ARC Centre of Excellence for Design in Light Metals, Monash University, Melbourne, Australia.

(a) Huda.Al-Salihi@monash.edu.

(b) Colleen.Bettles@monash.edu.

(c) Barry.Muddle@monash.edu. 


\section{INTRODUCTION}

Ti-10V-2Fe-3Al alloy, with low density and comparatively high strength, has been identified as a primary structural material for aircraft in aerospace applications [1]. However, one of the most significant obstacles to the wide and fast utilization of this alloy is related to damage, which could result in a progressive degradation of the metal performance and lead to the failure of the parts during the forming processes [2]. Plastic deformation of titanium alloys is a mutual coupling process of mechanical properties and microstructural evolution. For this reason, great attention is given in the scientific literature to understanding the deformation behaviour for Ti-10V-2Fe$3 \mathrm{Al}$ alloy during hot deformation process. However, there are few studies paying attention on the interactions between the processing parameters and microstructural evolution of Ti-10-2-3 alloy during hot deformation process. So it is essential to characterize the effect of thermomechanical parameters such as deformation temperature and strain rate on the microstructure of Ti-10-2-3 alloy for the optimization of the hot deformation process for this alloy.

Flow behaviour during hot deformation processing is often considered to be complicated due to the occurrence of both hardening and softening during processing. The characteristics of flow curves are generally a direct consequence of microstructural changes during processing involving work hardening, dynamic recrystallization and dynamic recovery [3].

Phenomenological equations are often used to describe the interaction effects of the processing parameters during plastic deformation. Different values for the ZenerHolloman parameter $Z$ can be obtained depending on the activation energy for each process condition. Thus, the main objective of the present study is to characterize the flow behaviour of $\mathrm{Ti}-10 \mathrm{~V}-2 \mathrm{Fe}-3 \mathrm{Al}$ alloy at different hot compression conditions and analyze the influence of processing parameters on the kinetic variables and microstructural evolution. A reliable phenomenological equation will be developed in order to understand the deformation behaviour in depth and optimize the deformation parameters. In addition, an attempt has been made to investigate free surface cracks at certain conditions.

\section{EXPERIMENTAL PROCEDURES}

The alloy Ti-10V-2Fe-3Al was received from WTI engineering, as forged with a chemical composition of (wt-\%): 9.70 pct V, 1.84 pct Fe, and 3.04 pct Al. The transus temperature was considered to be $800 \pm 5{ }^{\circ} \mathrm{C}$ [4-5]. Cylindrical specimens with 4 $\mathrm{mm}$ diameter and $6 \mathrm{~mm}$ height were machined from the forged ingot. Prior to hot compression testing, all the specimens underwent a $\beta$-solutionising at $870^{\circ} \mathrm{C}$ for 2 hrs, followed by water quenching. Hot compression tests were carried out in argon atmosphere using an Infrared Clam Shell Furnace connected to an Instron testing machine. Seven temperatures $\left(760,775,790,800,810,850,870^{\circ} \mathrm{C}\right)$ and three strain rates $\left(0.01,0.1,1 \mathrm{~s}^{-1}\right)$ were investigated. Glass lubricant was used to reduce the friction between platens and the specimens. Deformation temperature was measured by thermocouples which were spot welded to the outer surface of the top platen at the mid thickness. Each specimen was heated up to the deformation 
temperature at a heating rate of $5^{\circ} \mathrm{C} / \mathrm{s}$ and soaked for $2 \mathrm{~min}$ at the deformation temperature prior to upsetting to an engineering strain of 0.6. After completion of the isothermal compression, the deformed specimens were air cooled to room temperature and then axially sectioned parallel to the compression axis. The cut surface was prepared for optical microstructure examination by using standard metallographic techniques. Etching was carried out with Kroll's solution $\left(5 \% \mathrm{HNO}_{3}\right.$, $10 \% \mathrm{HF}, 85 \%$ water) for (2-4) sec. Electron back scattered diffraction (EBSD) and scanning electron microscopy (SEM) were also employed for the microstructural characterization.

\section{RESULTS}

\section{Mechanical Behavior}

Typical true stress - strain curves of Ti-10V-2Fe-3Al alloy for the investigated temperatures and strain rates are shown in Fig.1. It is obvious to see the sensitive reliance of flow stress on the deformation temperature and strain rate. Higher stress was achieved at lower temperature and higher strain rate. The general trend for all conditions is rapid hardening followed by either softening or steady state flow. At a given temperature, flow stress increases as strain rate increases. It appears that flow softening is most pronounced at $760^{\circ} \mathrm{C}$.

Figure 2 summarizes the effect of deformation temperature and strain rate on the flow stress, showing an obvious decline in the stress values as the deformation temperature increases in all strain rates. However, the rate of decline in the flow stress is less at high deformation temperatures.

\section{Phenomenological Equations}

The relationship between the flow stress, deformation temperature and the strain rate can be described by several different phenomenological equations [6-10] :-

The power law, which is applicable at low stresses and successfully used to describe the creep process:

$$
\dot{\varepsilon}=A_{1} \sigma^{n_{1}} \exp (-Q / R T)
$$

$\mathrm{n}_{1}$ can be determined by the plot of $\ln \varepsilon$ versus $\ln \sigma_{p}$, at constant $\mathrm{T}$.

The exponential law is applicable for high stresses:

$$
\bar{\varepsilon}=A_{2} \exp (\beta \sigma) \exp (-Q / R T)
$$

$\beta$ can be determined from the plot of $\ln \varepsilon$ versus $\sigma_{p}$.

The hyperbolic-sine law is applicable for a wide range of stresses. It is now well accepted that the influence of strain rate and temperature on flow stress during hot 
deformation could be satisfactorily expressed with the equation proposed by Sellars and Tegart which takes hyperbolic form [11], as is shown in equation [3]:

$$
\dot{\varepsilon}=A[\sinh (\alpha \sigma)]^{n} \exp (-Q / R T)
$$

$A_{1}, A_{2}, A, n_{1}, \beta$ and $n$ are the material constants and $\alpha$ is the stress multiplier, $\dot{\varepsilon}$ is the strain rate, $Q$ is the apparent activation energy $(\mathrm{J} / \mathrm{mol}), R$ is the universal gas constant $(8.314 \mathrm{~J} / \mathrm{mol} . \mathrm{K})$, and $T$ is the absolute temperature $(\mathrm{K})$. An Arrhenius equation can be used to describe the relationship among the strain rate, the flow stress and the temperature at high temperature through the Zener-Holloman parameter (Z) as follows [8-9, 12]:

$$
Z=\dot{\varepsilon} \exp (Q / R T)
$$

By combining equation [3] and equation [4], we can relate the strain rate, temperature and the flow stress to Zener-Holloman parameter $(Z)$ :

$$
Z=\dot{\varepsilon} \exp (Q / R T)=A[\sinh (\alpha \sigma)]^{n}
$$

Activation energy describes the activation barrier that atoms need to overcome to allow deformation. The apparent activation energy for hot deformation $Q$ is dependent on the chemical composition and microstructure of the hot formed material [13-14].

In the present study, peak stress $\sigma_{p}$ was taken for the $\sigma$ term in the above equations. The stress multiplier $\alpha$ is an adjustable constant that brings the values of $\alpha \sigma$ into the suitable range to obtain the best fit of the slopes. Thus, the optimum $\alpha$ value should be obtained by plotting In $\sinh (\alpha \sigma)$ vs In $\dot{\varepsilon}$ at different temperatures and peak stress. The parallel degree decides the optimal value of $\alpha$.

The first assumption of the stress multiplier $\alpha$ can be obtained from the following equation:

$$
\alpha=\beta / n_{1}
$$

Then the value of $\alpha$ was taken from Eq. (6) as a first approximation, which was then iterated to obtain the optimum values of $\alpha$, n. Plots of $\ln [\sinh (\alpha \sigma)]$ vs $\ln \varepsilon$ at selected values of strain rate and different temperatures are shown in Fig.3(b). When the seven lines of these temperatures are pretty closed to parallel, the optimal value of $\alpha$ can be obtained [10, 15-18].

Activation energy on the other hand, was derived from Arrhenius plots of In (Sinh $(\alpha \sigma))$ versus $1 / \mathrm{T}$, as is shown in Fig.3. Thus, the In (Sinh $(\alpha \sigma))$ vs In $\dot{\varepsilon}$ plots take the form of a group of parallel and straight lines at high temperatures, which indicate that the peak stress for the Ti-10-2-3 alloy can be represented by a Zener-Holloman parameter in the hyperbolic sine -type equation, as shown in Fig.4. 
Figure 5 shows the actual fluctuation of the activation energy values with the deformation temperatures and strain rates. Obviously, the higher activation energy value was observed at the temperature $800{ }^{\circ} \mathrm{C}$ in all strain rates, which represents the transformation region from $\alpha+\beta$ to the $\beta$ phase. However, lower activation energies were obtained when the strain rate was $0.1 \mathrm{~s}^{-1}$ at all deformation temperatures. In addition, it appears that the activation energy is at its lowest at the temperature $850^{\circ} \mathrm{C}$ for all strain rates as shown in Fig.5 (b).

\section{Microstructural Observation}

A representative optical micrograph of the the initial microstructure of Ti-10-2-3 alloy after solution treatment at $870^{\circ} \mathrm{C}$ followed by water quenching, is shown in Fig.6. It was observed that the microstructure of $\beta$-ST with fast cooling consisted of large equiaxed $\beta$ grains and the grain size varied between (193-210) $\mu \mathrm{m}$.

Figure 7 illustrates the optical microstructure of the samples deformed at the temperatures below beta transus, in particular at $760^{\circ} \mathrm{C}, 790^{\circ} \mathrm{C}$ and $800^{\circ} \mathrm{C}$. The morphology of the deformed grains ranged between elongated in the direction perpendicular to compression axis and equiaxed grains with their boundaries. The boundaries of elongated grains are nearly straight and no recrystallized grains at any strain rates were observed.

The microstructures of those samples processed above beta transus are totally different from that in the $\alpha+\beta$ phase region. Small grains have developed within the original grains during hot compression at the temperatures $810^{\circ}, 850^{\circ} \mathrm{C}$ and $870^{\circ} \mathrm{C}$ which suggests dynamic recrystallization, as shown in Fig.8. However, there are still a large number of elongated grains in the deformed microstructures.

The volume fraction of recrystallized grains increases as the deformation temperature increases at higher strain rate. Fig.9 shows that DRX is most pronounced at higher strain rate and temperatures above $\beta$ transus.

\section{Damage}

As expected, surface cracking was observed at lowest temperature $760^{\circ} \mathrm{C}$ and highest strain rate $1 \mathrm{~s}^{-1}$, as shown in Fig.10 (a). The SEM image shows voids in the grain boundaries, indicating that grain boundaries are preferable sites for void nucleation and coalescence and subsequent crack initiation, as shown in Fig.10 (b).

\section{DISCUSSION}

\section{True Stress-Strain Curves}

Deformation behavior at temperatures below the beta transus $(760-790){ }^{\circ} \mathrm{C}$ is characterized by initial sharp work hardening. The occurrence of this initial sharp peak phenomenon can be related to the presence of a particles. During the initial stages of deformation there is an increase in the flow stress as dislocations interact and multiply. As the process progresses the increasing dislocation density results in an increase in the rate of dynamic recovery which leads to the development of the 
microstructure. Thus, it is proposed that alpha phase plays an important factor in dislocation initiation $[8,13]$.

Obviously, the flow softening seems more pronounced at lower temperatures especially at $760^{\circ} \mathrm{C}$, as is shown in Fig. 1 , which suggests dynamic recovery has occurred, and there are no recrystallized grains observed in all strain rates. Previous work [19], suggests that flow softening behavior is attributed to deformation heating and also to the microstructural instabilities inside the material, such as dynamic recrystallization, texture formation, and dynamic recovery.

Deformation at higher temperatures (above $\beta$ transus) specifically at $850^{\circ} \mathrm{C}$ and $870^{\circ} \mathrm{C}$, shows steady state flow after reaching peak stress at all strain rate values, as shown in Fig.1. At any single strain rate, as expected, a lower flow stress was obtained at higher temperatures.

From the above, it seems that flow softening is a common characteristic of the true stress-strain curves of Ti-10-2-3 alloy at lower temperatures. At the onset of deformation, work hardening exceeds the dynamic softening due to the rapid multiplication of dislocations, leading to a rapid increase of flow stress. Whereas, it can be concluded that steady state flow occurs at high temperatures over all strain rates, while oscillations and softening are characteristic for the deformation at lower temperatures.

Figure 2 presented the relationship between the deformation temperature and flow stress at different strain rates. It can be seen that flow stress increased as the strain rate increased due to the increase of dislocation density and the dislocation multiplication rate [8]. When the flow stress relative to the temperature is compared to the flow stress relative to the strain rate, there is no doubt that the effect of temperature on the flow stress is more pronounced than that of the strain rate.

In terms of the activation energy value $Q$, it can be seen from Fig.5 that the value of $Q$ varied depending on the processing parameters. Generally, it seems that the average value of activation energy at lower temperatures $\left(760,775,790^{\circ} \mathrm{C}\right)$ at all strain rates is the same as that at the temperatures $850^{\circ} \mathrm{C}$ and $870^{\circ} \mathrm{C}$.

In addition, the effect of phase transformation on the activation energy value seems very obvious in Fig.5. Higher activation energy value was observed in the transus region at the temperature $800^{\circ} \mathrm{C}$ in all strain rates since this temperature represents the transus temperature where the transformation process from $\alpha+\beta$ to $\beta$ phase occurs. Therefore, it appears transformation of $\alpha$ phase to $\beta$ phase increases the bulk activation energy.

Also, it is obvious to see the trends of the activation energy are the same for each strain rate, as shown in Fig.5 (b). Lower activation energy obtained when the strain rate was 0.1 and then slightly increased when the strain rate increased to $1 \mathrm{~s}^{-1}$. This behaviour indicates that there are less difficulties with processing when the strain rate was $0.1 \mathrm{~s}^{-1}$. In addition, there is some convergence of the activation energy values when the strain rate was 0.01 and $1 \mathrm{~s}^{-1}$. 
Zener-Holloman parameter $Z$, embracing the relative influences of strain rate and temperature in the hot working process has been plotted versus In sinh $\left(\alpha \sigma_{\mathrm{p}}\right)$ in Fig.4. The plot brings all the peak stress data into a single line and the linear relationship is satisfied between In sinh $\left(\alpha \sigma_{p}\right)$ and Zener- Holloman parameter. In conclusion, the hyperbolic-sine relationship Eq. (5) can be used to describe the elevated flow behaviour of Ti 10-2-3 titanium alloy.

\section{Microstructural Evolution}

The deformed microstructures of Ti-10-2-3 alloy including the size and morphology as well as the volume fractions of the grains are extremely affected by the deformation temperature and the stain rate as shown in Figs. 7, 8, 9. Thus, it could be said that the microstructure of the samples which were deformed either in the $\beta$ or in the $(\alpha+\beta)$ phase at strain $0.1,0.01$ and $1 \mathrm{~s}^{-1}$ revealed meaningful strain localization effects.

From Fig.7, original grain boundaries can be clearly observed and a recovered microstructure observed at lower deformation temperatures which suggest that dynamic recovery occurs through the coalescence of grains and grain growth under the driving force of the energy stored in the recovered structure boundaries.

Meanwhile, dynamic recrystallization is frequently observed at higher deformation temperatures ( above beta transus) and relatively higher strain rate specifically when the deformation temperatures were $810^{\circ} \mathrm{C}, 850^{\circ} \mathrm{C}$ and $870^{\circ} \mathrm{C}$ with strain rate $1 \mathrm{~s}^{-1}$ as shown in Fig.8. The volume fraction and the size of the recrystallized grains increased significantly and the necklace structure could be observed noticeably at $870^{\circ} \mathrm{C}$.

From the above it seems that the progress of recrystallization is extremely reliant on the temperature and strain rate as shown in Fig.9. It is obvious to see that the volume fraction of $\mathrm{DRX}$ at $810^{\circ} \mathrm{C}$ is relatively small compared with the recrystallized grains at $850^{\circ} \mathrm{C}$ and $870^{\circ} \mathrm{C}$. As the deformation temperature increased to $870^{\circ} \mathrm{C}$ at strain rate $1 \mathrm{~s}^{-1}$, a large number of new recrystallized grains (more than $50 \%$ structure) emerged on the original grain boundaries, and the necklace structure started to form around the initial grains and grain boundaries.

Below beta transus, at temperatures $760,775,790$ and $800^{\circ} \mathrm{C}$ there is not enough strain energy to cause recrystallization, and no recrystallized grains were observed. Just above beta transus temperature, a few areas in the material will have sufficient strain energy to start the recrystallization process. Thus, a few recrystallized grains formed and grew to consume the unrecrystallized regions.

It should be noted that dynamic recrystallization usually originates at high angle boundaries which are preferable sites. These may be the original boundaries, boundaries of recrystallized grains, or high angle boundaries created during straining (those associate with deformation bands and twins) [20]. Higher temperatures provide more energy for recrystallized boundary migration leading to a larger grain size. The reason for that is attributed to the diffusion process which increases as the deformation temperature increase [20]. 
Strain rate also has a remarkable effect on the microstructure during hot deformation. It is believed that with a decrease of strain rate, whilst providing sufficient time for nucleation and growth, there is insufficient accumulation of stored energy[21].

At higher strain rates, the dislocation density is increased and recrystallization readily occurs [21]. It can be concluded that lower strain rates are not sufficient for the occurrence of DRX completely. In addition, it seems to be that the degree of DRX increases as strain rate increase as well, as shown in Fig.9. With increasing strain rate, more nuclei become available and the recrystallized grain size increases. This is consistent with the present results that the higher strain rates lead to the dynamic recrystallization.

On the other hand, at high strain rate and $\mathrm{T}=870^{\circ} \mathrm{C}$, there is still not enough time to have a fully recrystallized structure. There are insufficient nuclei and the time is too short for growth of the new $\beta$ grains, and therefore, the recrystallized $\beta$ grains exhibited equiaxed or globularized structures and a small size.

\section{Fracture Observation}

In the present study, longitudinal surface cracking was observed in just one condition. This is due to the development of circumferential stresses caused by the barrelling shape. As expected, surface cracks were observed on the free surface under the condition of faster strain rate and lower temperature, where the deformation temperature was $760^{\circ} \mathrm{C}$ and strain rate was $1 \mathrm{~s}^{-1}$, as shown in Fig.10, due to the fact that a cracking domain is characterized as a steep change in the plasticity with decreasing deformation temperatures and increasing strain rate [12]. The existence of cracks in this particular condition could be attributed to the presence of the high volume fraction of $\alpha$ particles in the $\beta$ matrix as EBSD results indicated, Fig.11.

Higher volume fractions of a provide additional impediments to slip during processing. In fact, slip transfer at $\alpha / \beta$ interfaces is difficult due to the much lower number of slip systems in the hcp a phase[1]. Therefore, crack initiation in this condition is more likely than other temperatures such as $775^{\circ} \mathrm{C}, 790^{\circ} \mathrm{C}$ where the volume fraction of $\alpha$ reduces as deformation temperature increases.

From Fig.10 (b), it is obvious that there are a large number of voids initiated on the grain boundaries, which indicates that grain boundaries are the preferable sites for void initiation, due to localized stress concentration, especially in the triple points. As these voids coalesce, cracks are formed. Thus, intergranular cracks are likely to occur.

\section{CONCLUSIONS}

1- Flow softening was observed at $760^{\circ}$, which suggests dynamic recovery occurred. However, steady state flow was achieved at high deformation temperatures at $810^{\circ} \mathrm{C}, 850^{\circ} \mathrm{C}, 870^{\circ} \mathrm{C}$ where extensive recrystallization was observed. 
2- Higher value of activation energy was obtained at temperature $800^{\circ} \mathrm{C}$, the reason for that is attributed to transformation of $\alpha+\beta$ to $\beta$ phase.

3- Dynamic recrystallization is usually initiated at pre-existing boundaries therefore intergranular nucleation becomes more important.

4- Surface cracking was detected at deformation temperature $760^{\circ} \mathrm{C}$ with strain rate $1 \mathrm{~s}^{-1}$. Existence cracks in this particular condition could be attributed to the presence of high volume fraction of $\alpha$ particles in the $\beta$ matrix as EBSD results indicated.

5- Grain boundaries are the favorable sites for void initiation, due to localized stress concentrations in particular in the triple points.

\section{ACKNOWLEDGEMENTS}

The authors express their appreciation to Deakin University for providing access to compression testing equipment. This research was financially supported by the ARC Centre of Excellence for Design in Light Metals and Iraqi government.

\section{REFERENCES}

[1] Leyens C. and Peters M.: Titanium and Titanium Alloys: Fundamentals and Applications. Wiley-VCH GmbH \& Co. KGaA, Weinheim, 2003.

[2] Hambli R. and Badie-Levet D.: Damage and fracture simulation during the extrusion processes. Comput. Methods Appl. Mech. Engrg, Vol. 186, pp 109120, (2000).

[3] Liao S. I., Zhang L. W., Yue C. X., Pei J. B. and Gao H. J.: Hot deformation behaviour and flow stress model of GCr15 bearing steel. J. Cent. South Univ. Technol.Vol.15, pp 575-580 (2008).

[4] Jakson J., Dashwood R., Christodoulou L. and Flower H.: The Microstructural Evolution of Near Beta Alloy Ti-10V-2Fe-3Al during subtransus forging. Metallurgical and Materials Transactions A. Vol. 36A, pp 1317-1327. (2005)

[5] Duerig T. W., Allison J. E. and Williams J. C.: Microstructural influences on fatigue crack propagation in Ti-10V-2Fe-3Al. Metallurgical Transactions A, Vol.16A, pp739-751, May (1985).

[6] Qiang B. R., Huang X. and Cao C. X.: Deformation behaviour and mechanisms of $\mathrm{Ti} 1023$ alloy. Transactions of Nonferrous Metals Society. Vol.16, pp 274-280 (2006).

[7] Robertson D. G. and McShane H. B.: Analysis of high temperature flow stress of titanium alloys IMI 550 and Ti-10V-2Fe-3Al during isothermal forging. Materials Science and Technology, Vol.14, pp 339-345, April (1998).

[8] Duan Y. P., Li P., Xue K. M., Zhang Q. and Wang X. X.: Flow behaviour and microstructure evolution of TB8 alloy during hot deformation process. Trans. Nonferrous Met. Soc., Vol. 17, pp 1199-1204 (2007). 
[9] Fang C., Zhang J., Liao A. L., Xue S. Z., Yuan F. Q. and Pan F. S.: Hot compression deformation characteristics of Mg-Mn alloys. Trans. Nonferrous Met. Soc., Vol. 20, pp 1841-1845 (2010).

[10] Mirzadeh H., Najafizadeh A. and Moazeny M.: Flow curve analysis of 17-4 $\mathrm{PH}$ stainless steel under hot compression test. Metallurgical and Materials Transactions A, Vol. 40A, pp 2950-2958, Dec. (2009).

[11] Sellars C.M. and McTegart W.J.: On the Mechanism of Hot Deformation. Acta Metallurgica ,Vol.14, pp 1136-1138 (1966).

[12] Balasubrahmanyam V. V., and Prasad Y. V. R. K.: Hot deformation mechanisms in metastable beta titanium alloy Ti-10V-2Fe-3Al. Materials Science and Technology, Vol. 17, pp 1222-1228, October (2001).

[13] Franoush H., Momeni A., Dehghani K., Mohandesi J. A. and Keshmiri H.: Hot deformation characteristics of 2205 duplex stainless steel based on the behaviour of constituent phases. Materials and Design, Vol. 31, pp 220-226 (2010).

[14] Schindler I., Sumsal V., Cagala M., Kulveitova H. and Knapinski M.: Determination of activation energy in hot forming of alloy Fe-40Al type. Metallurgical and Materials Transactions a-Physical Metallurgy and Materials Science, Vol.5, pp18-25 (2011).

[15] Samantaray D., Mandal S. and Bhaduri A. K.: Constitutive analysis to predict high-temperature flow stress in modified 9Cr-1Mo (P91) steel. Materials and Design, Vol. 31, pp 981-984 (2010).

[16] Banerjee S., Robi P.S., Srinivasan A. and Kumar L.P.: High temperature deformation behaviour of Al-Cu-Mg alloys micro-alloyed with Sn. Materials Science and Engineering A, Vol.527, pp 2489-2503 (2010).

[17] McQueen H.J. and Ryan N.D.: Constitutive analysis in hot working. Materials Science and Engineering A, Vol. 322, pp 43-63 (2002).

[18] Jin N., Zhang H., Han Y., Wu W. and Chen J.: Hot deformation behaviour of 7150 aluminum alloy during compression at elevated temperature. Materials Characterization, Vol.60, pp 530-536 (2009).

[19] Zhang H., Li L., Yuan D. and Peng D.: Hot deformation behaviour of the new Al-Mg-Si-Cu aluminum alloy during compression at elevated temperature. Materials characterization, Vol. 58, pp 168-173 (2007).

[20] Humphreys F. J. and Hatherly M.: Recrystallization and related annealing phenomena, $2^{\text {nd }}$ edition, Elsevier, Oxford, England, (2004).

[21] Weixin Y., Miaoquan L. and Jiao L.: Effect of processing parameters on microstructure and mechanical properties in high temperature deformation of Ti-6Al-4V alloy. Rare Metal Materials and Engineering, Vol. 38, Issue 1, pp 19-24, January (2009). 


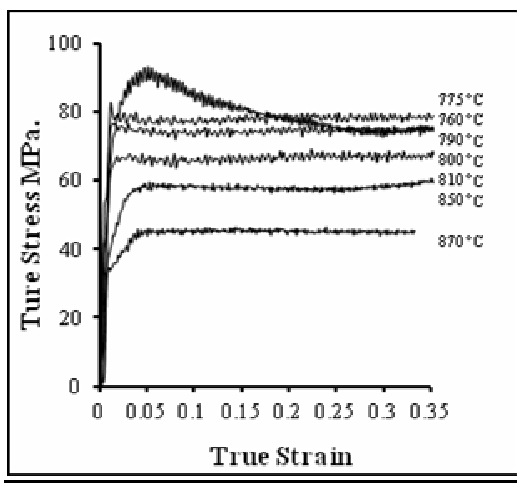

(a)

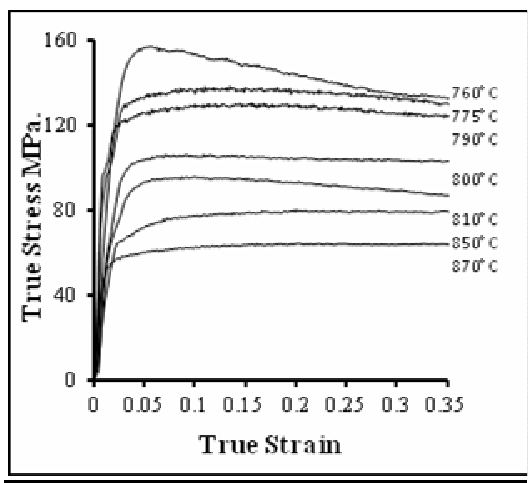

(b)

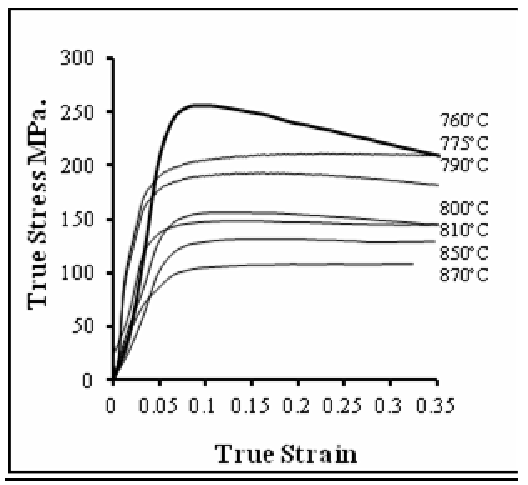

(c)

Fig.1. Experimental true stress-true strain curves of Ti-10-2-3 alloy at different strain rates and temperatures: (a) $0.01 \mathrm{~s}^{-1}$, (b) $0.1 \mathrm{~s}^{-1}$, (c) $1 \mathrm{~s}^{-1}$

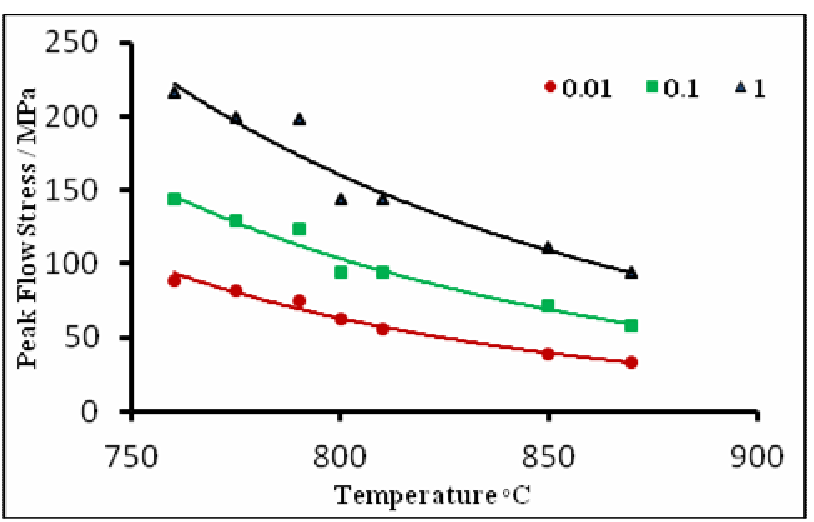

Fig.2 Variation of flow stress with temperature at different strain rates.

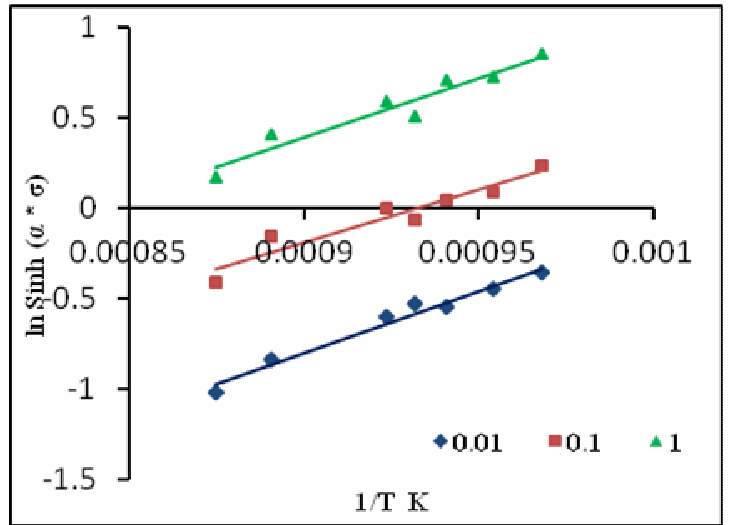

(a)

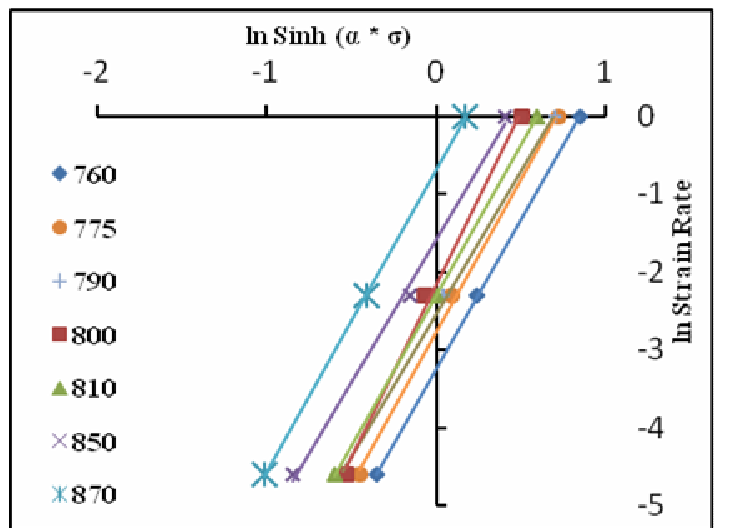

(b)

Fig .3. Evaluating the value of (a) $n$ and $\ln A$ by fitting $\ln \varepsilon-\ln [\sinh (\alpha \sigma)]$, (b) $Q$ by Fitting In $[\sinh (\alpha \sigma)]-1 / \mathrm{T}$. 


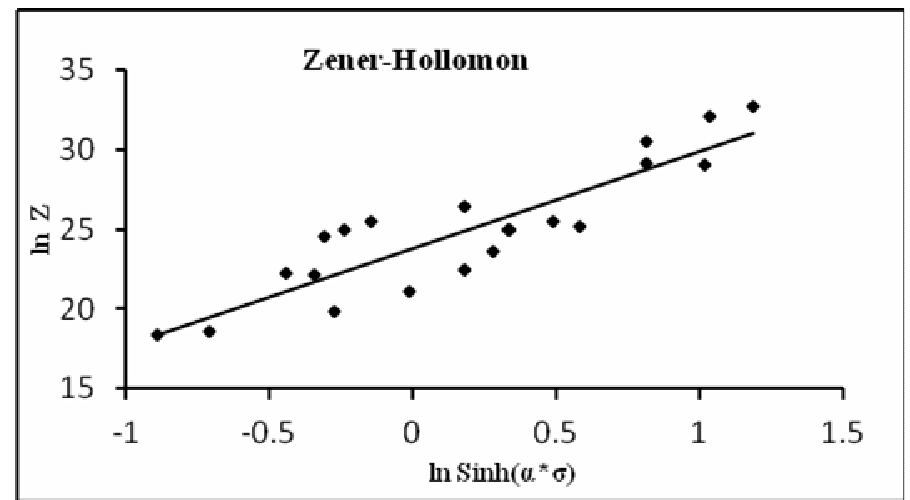

Fig.4. Relationship between $\mathrm{Z}$ parameters and peak stress for all T and $\dot{\varepsilon}$.

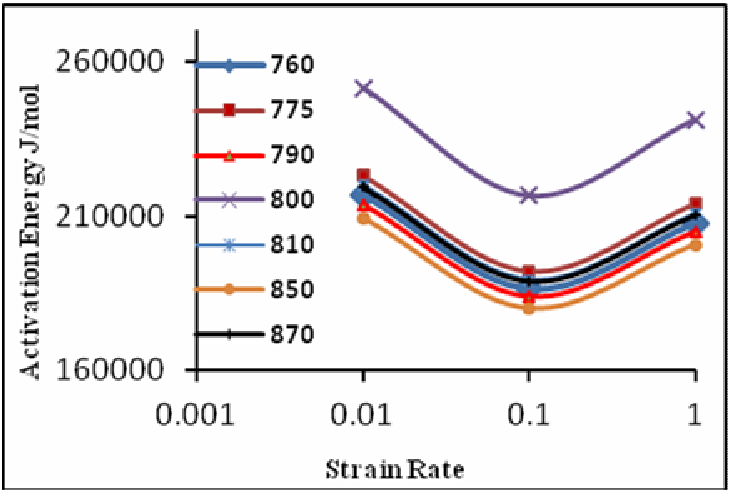

(a)

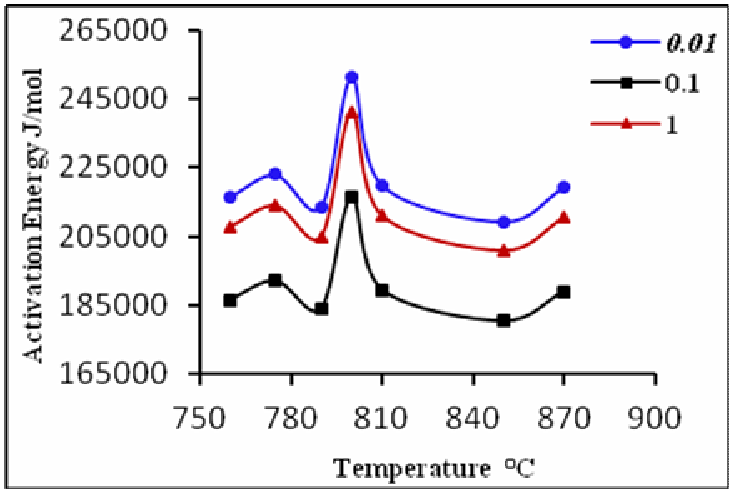

(b)

Fig. 5. The variation of the activation energy with (a) Temperature (b) Strain rate.

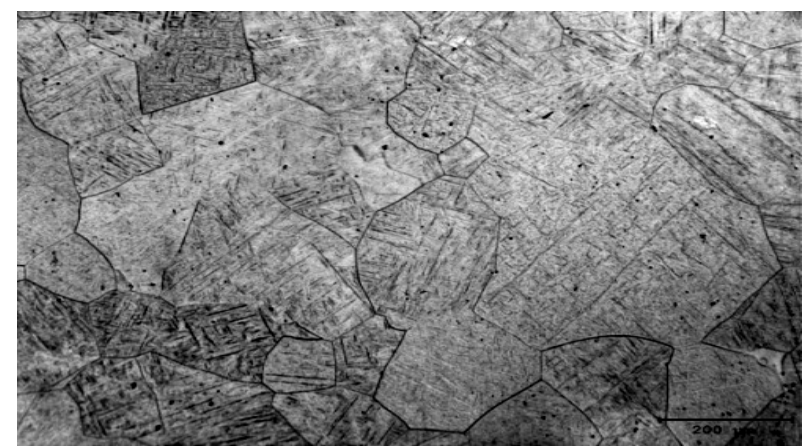

Fig. 6. Optical micrograph showing the microstructure of the $\beta$ - solutionised and quenched sample. 


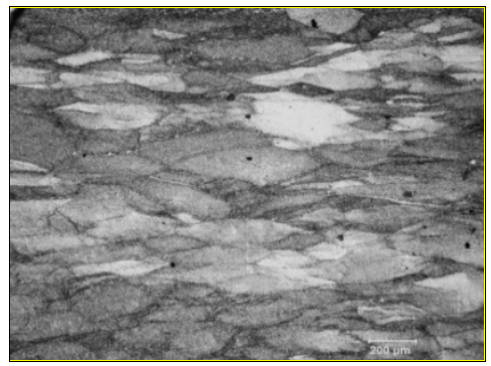

(a)

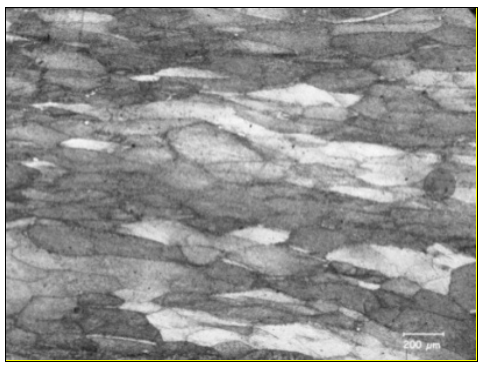

(b)

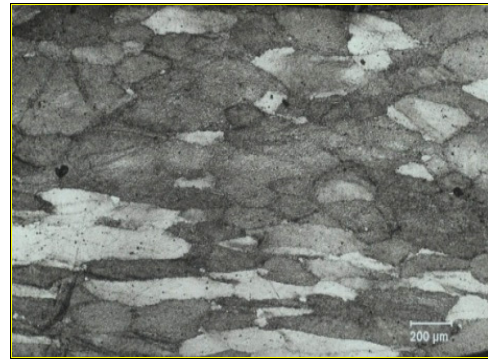

(c)

Fig. 7. Optical deformed microstructure of T-10-2-3 alloy at strain rate $1 \mathrm{~s}^{-1}$ and (a) $760^{\circ} \mathrm{C},(\mathrm{b}) 790^{\circ} \mathrm{C}$, (c) $800^{\circ} \mathrm{C}$.

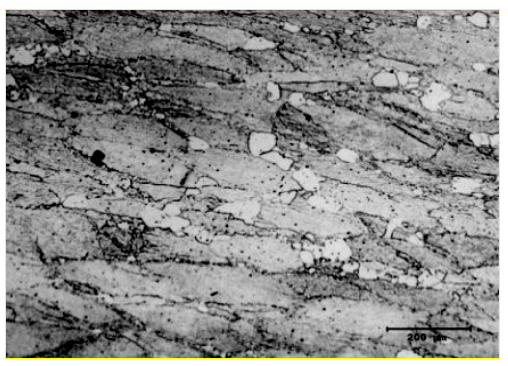

(a)

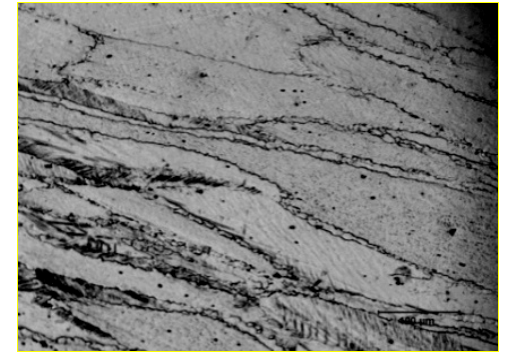

(b)

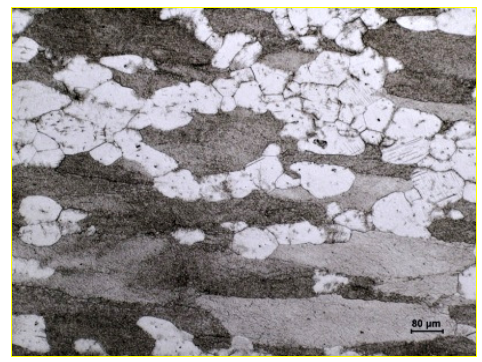

(c)

Fig. 8. Optical deformed microstructure of T-10-2-3 alloy at strain rate $1 \mathrm{~s}^{-1}$ and different tempratures (a) $810^{\circ} \mathrm{C}$, ( b) $850^{\circ} \mathrm{C}$, (c) $870^{\circ} \mathrm{C}$.

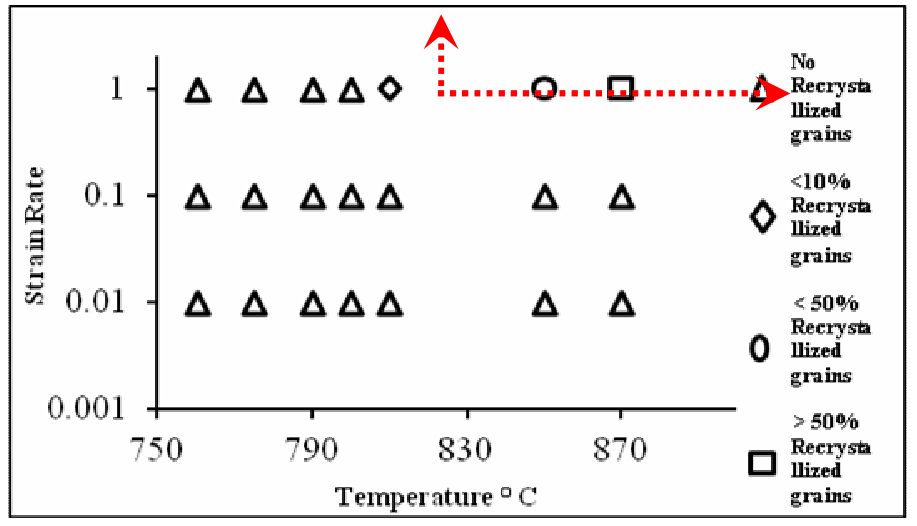

Fig. 9. Recrystallization map at different temperatures and strain rates. 


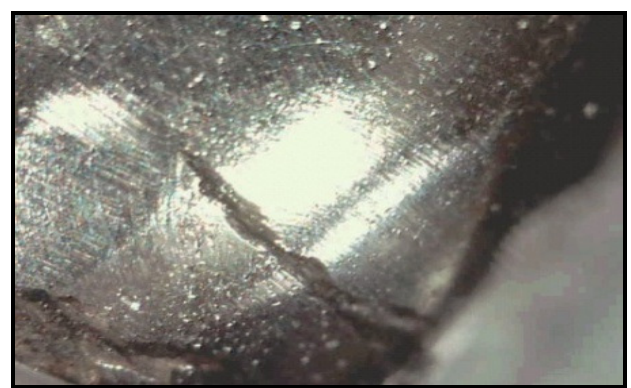

(a)

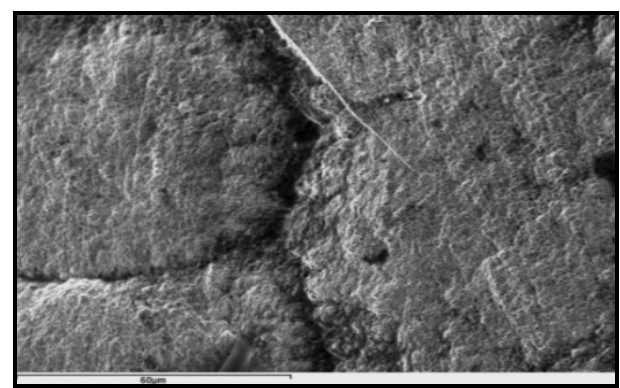

(b)

Fig. 10. (a) Optical microscope (b) SEM, at $760^{\circ} \mathrm{C}$ and $1 \mathrm{~s}^{-1}$.
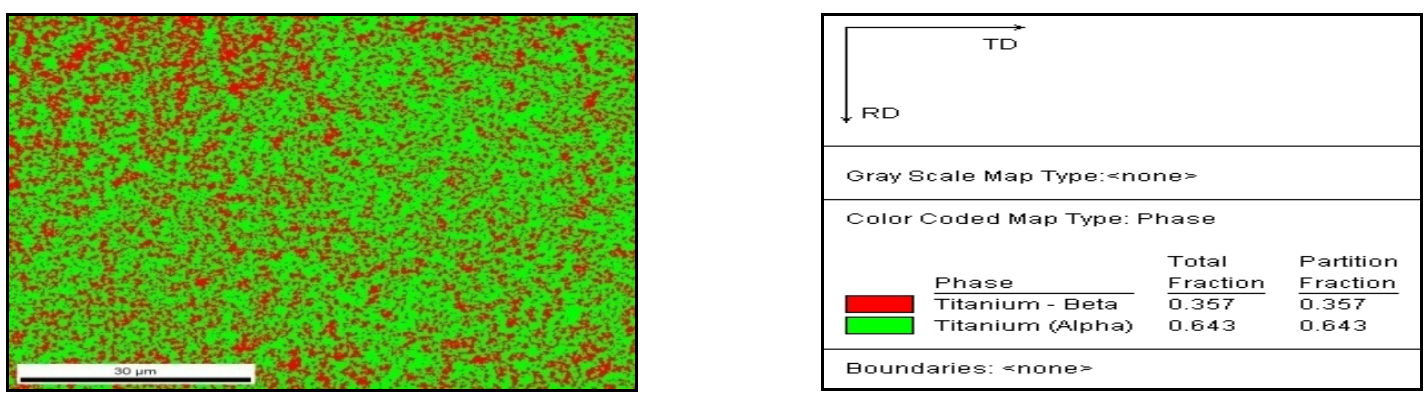

Fig. 11. EBSD for Ti-10-2-3 alloy deformed at $760^{\circ} \mathrm{C}$ and strain rat $1 \mathrm{~s}^{-1}$ 